\title{
A PROSPECTIVE CASE-CONTROLLED STUDY COMPARING PLATELET LEVELS AND PLATELET INDICES IN UNCOMPLICATED AND COMPLICATED ALCOHOL WITHDRAWAL SYNDROME(AWS)
}

Authors: Dr. Sagar Garag ${ }^{\# 1}$, Dr. Sameer Belvi Mangalwedhe ${ }^{2}$ \#Presenting author,1- Junior Resident Psychiatry, 2-Assistant professor, Karnataka Institute of Medical Sciences, Hubballi
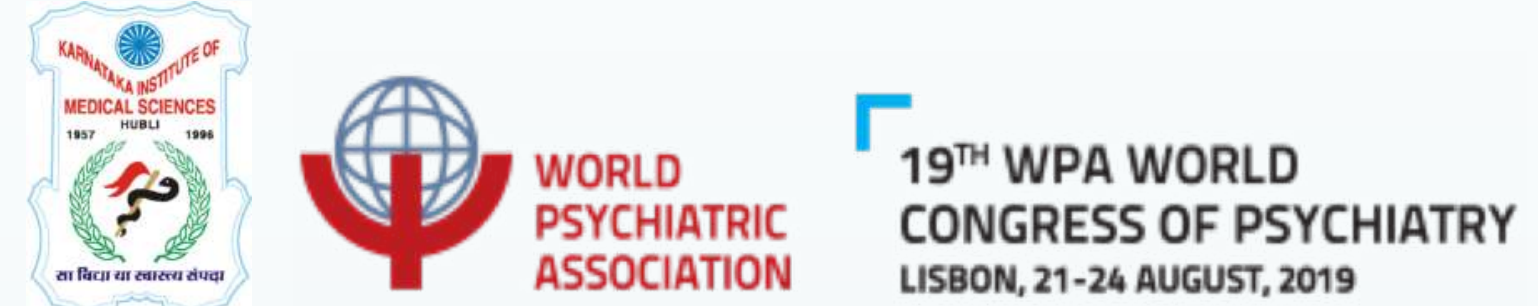

Background:In clinical practice, it is often difficult to evaluate the risk of DT inpatients with alcohol withdrawal seizures because they frequently present in altered consciousness, post-ictal confusion or poor general conditions.(1) There are substantial individual variations in the clinical manifestations of AWS. Prospectively identifying patients with increased risk of developing complications would have important preventive and therapeutic implications. (2)

Objectives:To compare the platelet count and platelet indices in uncomplicated and complicated alcohol withdrawal syndrome(AWS).

Materials and Methods: A prospective case-controlled study was conducted in tertiary hospital from December 2017 to December 2018, 200 cases were screened, 120 male cases were included in study. 60 were complicated and 30 uncomplicated AWS diagnosed as per ICD-10 were recruited in the study. 30age- and sex- matched healthy controls were recruited. Assessment tools were

1. Semi- structured socio-demographic proforma

2. Severity of Alcohol Dependence Questionnaire(SADQ)

3. Clinical Institute Withdrawal Assessment for alcohol scale, Revised(CIWA-Ar)

4. SYSEMEX XP-100 Fully automated differential hematology analyzer.

Pearson's Chi-square test, t-test, ANOVA, Kruskal Wallis test, Post-hoc pairwise analysis -Mann-Whitney U test were used in addition receiver operating characteristic curve (ROC) analysis was done.

Results: All male sample. $37.75 \pm 6.69$ was mean age. $64 \%$ hailed from rural domicile Low platelet count and low plateletcrit were associated with the subsequent development of complicated AWS and also are risk factors with high diagnostic sensitivity and specificity(tables\&figure).

\begin{tabular}{|c|c|c|c|c|}
\hline & $\begin{array}{l}\text { Control } \\
(n=30)\end{array}$ & $\begin{array}{c}\text { Un } \\
\text { complicate } \\
d \\
(n=30)\end{array}$ & $\begin{array}{l}\text { Convulsions } \\
\qquad(n=30)\end{array}$ & $\begin{array}{c}\text { Delirium } \\
(n=30)\end{array}$ \\
\hline $\begin{array}{l}\text { Platelet } \\
\text { count }\end{array}$ & $\begin{array}{c}271815.9^{a} \\
\pm \quad 70986.94\end{array}$ & $\begin{array}{l}137920.07^{b} \\
\pm 24353.53\end{array}$ & $\begin{array}{c}127209^{b} \pm \\
21325.28\end{array}$ & $\begin{array}{r}127751.13^{b} \\
\pm \quad 20244.16\end{array}$ \\
\hline Plateletcrit & $\begin{array}{c}0.27^{a} \pm \\
0.06\end{array}$ & $\begin{array}{c}0.28^{a} \pm \\
0.11\end{array}$ & $\begin{array}{c}0.21^{a} \pm \\
0.14\end{array}$ & $\begin{array}{c}0.21^{\mathrm{a}} \pm \\
0.13\end{array}$ \\
\hline
\end{tabular}

\section{* Significant}

Mean of Diagnosis groups sharing similar superscripts in each variable are not different by post hoc analysis (Tukey's test)

Mean of Diagnosis groups without similar superscripts in each variable are significantly different by post hoc analysis (Tukey's test)

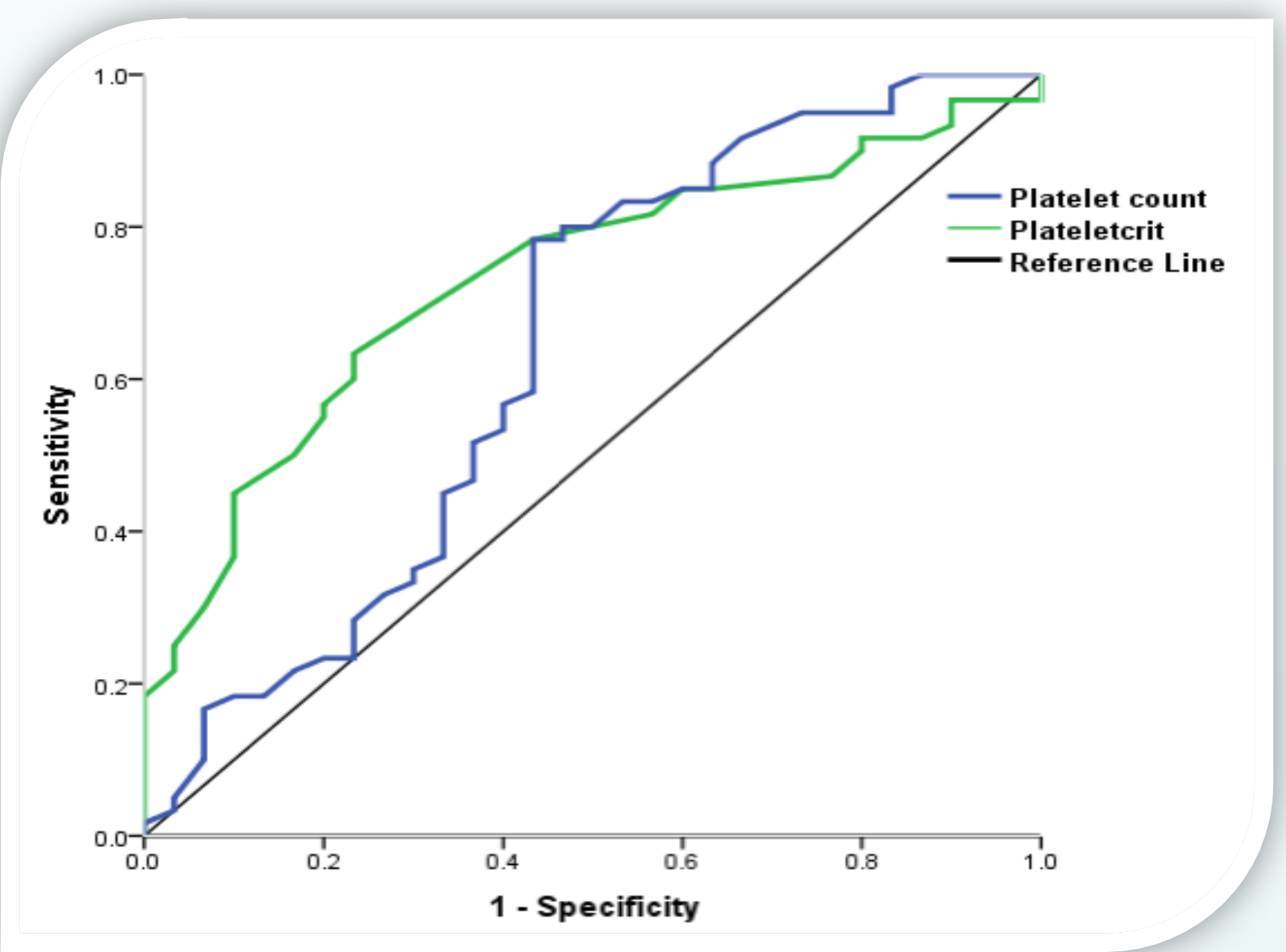

Figure. 1 ROC Curve and AUC

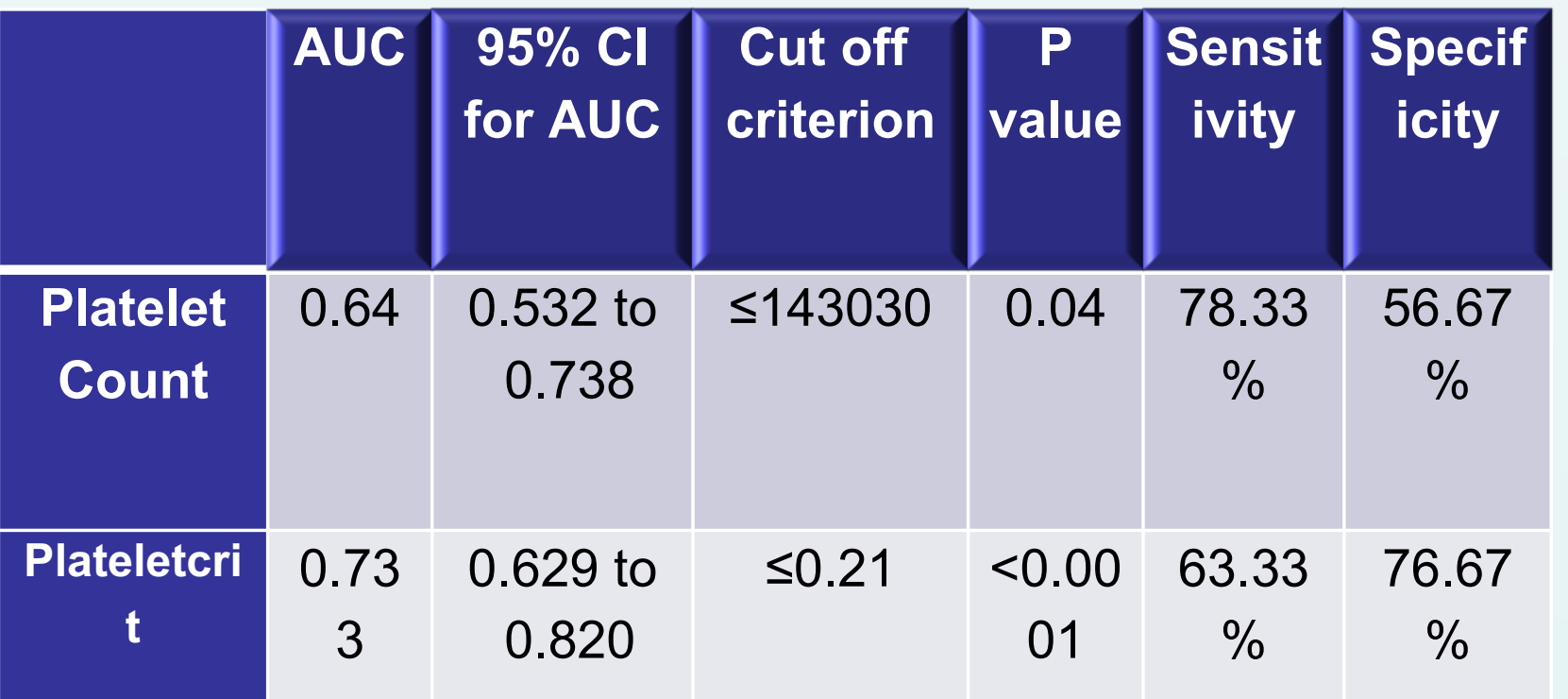

Table-2

Discussion Our study corroborates with earlier studies by Bergerren et al (3)and Kim et al (4) found Thrombocytopenia and Low plateletcrit in early alcohol withdrawal is associated with development of delirium tremens or seizure. Low platelet due to bone marrow toxicity possibly parallels the CNS toxicity.

Conclusion The study shows that platelet and platelet indices easily determined parameters are potential clinical predictors for the development of complicated AWS. This would be useful in prospective identification and intensive management of AWS.

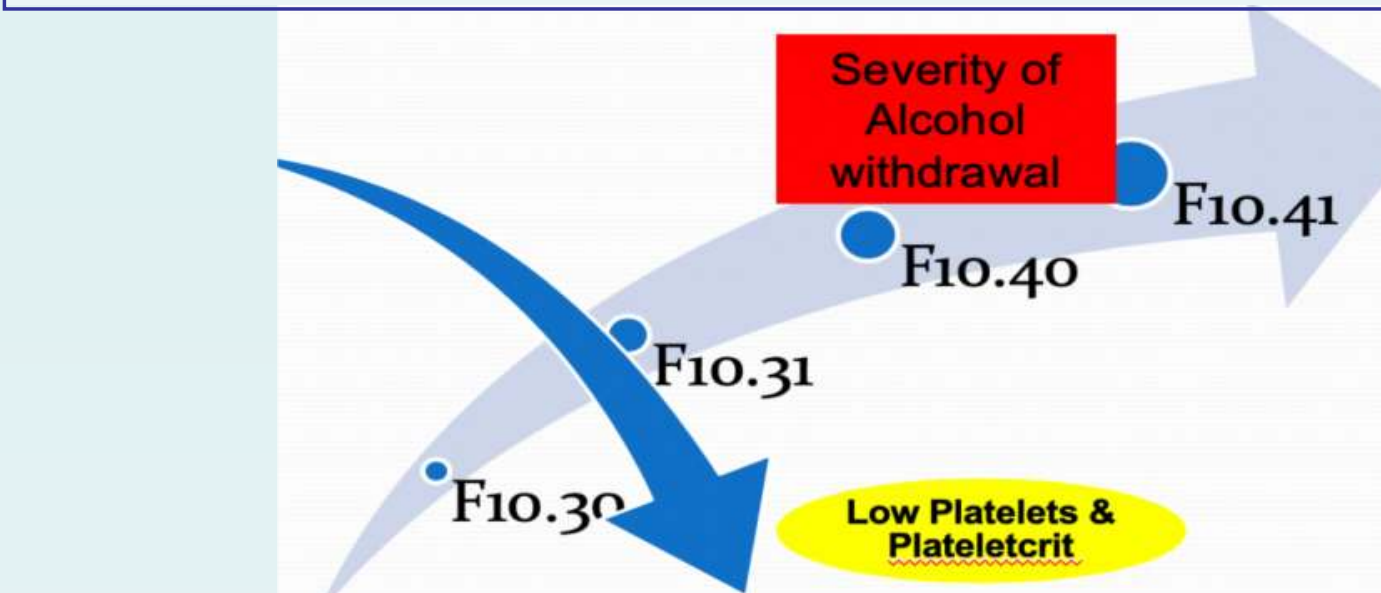

References

1.Wetterling T, Driessen M, Kanitz R-D, Junghanns K. The severity of alcohol withdrawal is not age dependent. Alcohol and Alcoholism 2001;36(1):75-8

2.Eyer F, Schuster T, Felgenhauer N, Pfab R, Strubel T, Saugel B, et al. Risk assessment of moderate to severe alcohol withdrawal—predictors for seizures and delirium tremens in the course of withdrawal. Alcohol and Alcoholism 2011;46(4):427-33.

3.Berggren U, Fahlke C, Berglund KJ, Blennow K, Zetterberg H, Balldin J. Thrombocytopenia in early alcohol withdrawal is associated with development of delirium tremens or seizures. Alcohol I\& Alcoholism 2009;44(4):382-6.

4.Kim DW, Kim HK, Bae E-K, Park S-H, Kim KK. Clinical predictors for delirium tremens in patients with alcohol withdrawal seizures. The American journal of emergency medicine 2015;33(5):701-4.

5. Harshe DG, Thadasare H, Karia SB, De Sousa A, Cholera RM, Kale SS, et al. A study of patterns of platelet counts in alcohol withdrawal. Indian journal of psychological medicine 2017;39(4):441. 